\title{
Why do children vomit after minor head injury?
}

\author{
F D Brown, J Brown, T F Beattie
}

\begin{abstract}
Objective-To determine factors associated with vomiting after minor head injury in a paediatric population with the intention of defining the role of vomiting in management decisions.

Methods-A prospective study of all patients presenting with minor head injury to the Royal Hospital for Sick Children, Edinburgh, between 1 May and 30 June 1997. Information regarding basic demographics, features of the head injury and past and family history was noted on a proforma. This included mechanism of injury, site of impact, presence or absence of scalp haematoma, skull fracture or brain injury and intrinsic factors such as age, family history of migraine and a personal history of migraine, its childhood variants and associated conditions. The relation between vomiting and these features was analysed using $\chi^{2}$ and Fisher's exact tests.

Results-563 children aged from birth to 13 years presented with minor head injury. Complete data were obtained on 463 patients. Some $15.8 \%$ vomited after minor head injury. Comparing vomiters with non-vomiters the only associated factors that could be identified were a past history of recurrent vomiting or motion sickness $(p=0.0035, p=0.036$ respectively $)$. Conclusions-Vomiting after minor head injury seems to be related to individual intrinsic factors rather than specific features of the head injury and its role in management decisions needs to be explored further.

(F Accid Emerg Med 2000;17:268-271)
\end{abstract}

Keywords: head injury; vomiting

Head injury is a common reason for children to present to accident and emergency (A\&E) departments. The vast majority of paediatric head injuries are minor ${ }^{1-3}$ with few developing serious complications such as haemorrhage or oedema. Vomiting commonly follows head injury and its implications are unclear. There is still much controversy surrounding its aetiology and the part it plays in making management decisions regarding paediatric minor head injury. ${ }^{2}{ }^{4}$

Past papers have considered the relation between vomiting and patients age or the site and mechanism of injury. They have postulated, but not proved, that younger children and those hit in the occipital region were more likely to vomit after a head injury. ${ }^{4}$ More recently, the role of intrinsic factors such as a migraine, its variants and associated conditions have been investigated in a study that found that a past or family history of migraine and a personal history of motion sickness were predictors of vomiting following a head injury. ${ }^{5}$ Our study prospectively assesses a paediatric population presenting to an $A \& E$ department with minor head injury with the aim of identifying any factors associated with vomiting and therefore defining its role in management desicions.

\section{Method}

All children (birth to 13 years old) who presented to the A\&E department of the Royal Hospital for Sick Children (RHSC), Edinburgh, from 1 May to 30 of June 1997 with head injury were considered eligible for inclusion in our study. Each patient was treated according to normal practice and, in addition, information regarding family history of migraine and personal history of migraine, its childhood variants and associated conditions was requested. A datasheet was completed by the staff member responsible for the patient, which recorded basic patient details, clinical details of the injury, any investigation results and the aforementioned details of past and family history. Details of vomiting after discharge or admission were completed by telephone.

The management policy in our hospital is to perform a skull radiograph if there is a history of loss of consciousness, clinical suggestion of a fractured base of skull, a large scalp haematoma, laceration or area of tenderness, a palpable bony defect, a history of possible penetrating injury or object trajectory injury and a suspicion of non-accidental injury. Children with skull fractures are admitted for observation and computed tomography (CT). Urgent CT is restricted to patients with an altered or deteriorating conscious state and those with a depressed fracture or penetrating injury. All children who were investigated with CT would be admitted for observation. All admissions are to the surgical wards.

For this study head injury was defined as any injury to the scalp including swelling, laceration, contusion or abrasion; clinical evidence of a fractured base of skull or a well documented history of a blow to the head in the absence of any identifiable lesion. Brain injury was defined as altered conscious state on examination or a history of loss of consciousness (LOC) or amnesia. Minor head injury was defined as a Glasgow Coma Score of 13 to 15. Posttraumatic vomiting was defined as vomiting occurring within 72 hours of the head injury that could not be attributed to any other cause. A diagnosis of migraine was accepted if the features fulfilled the International Headache Society's International Classification of 


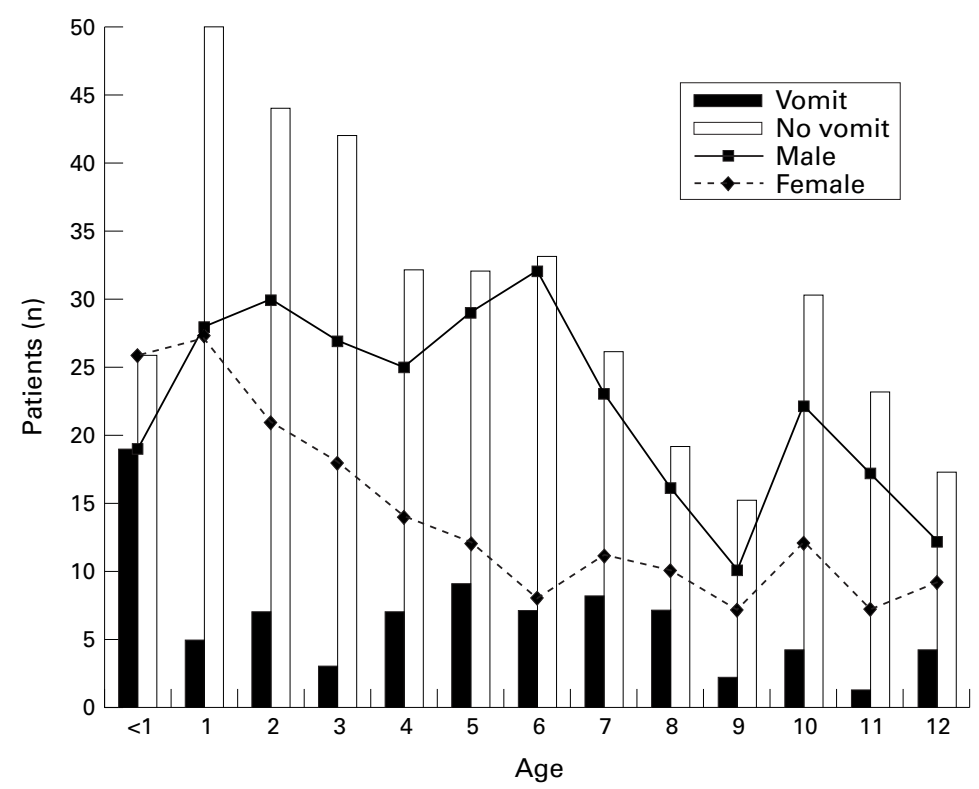

Figure 1 Age, sex and vomiting.

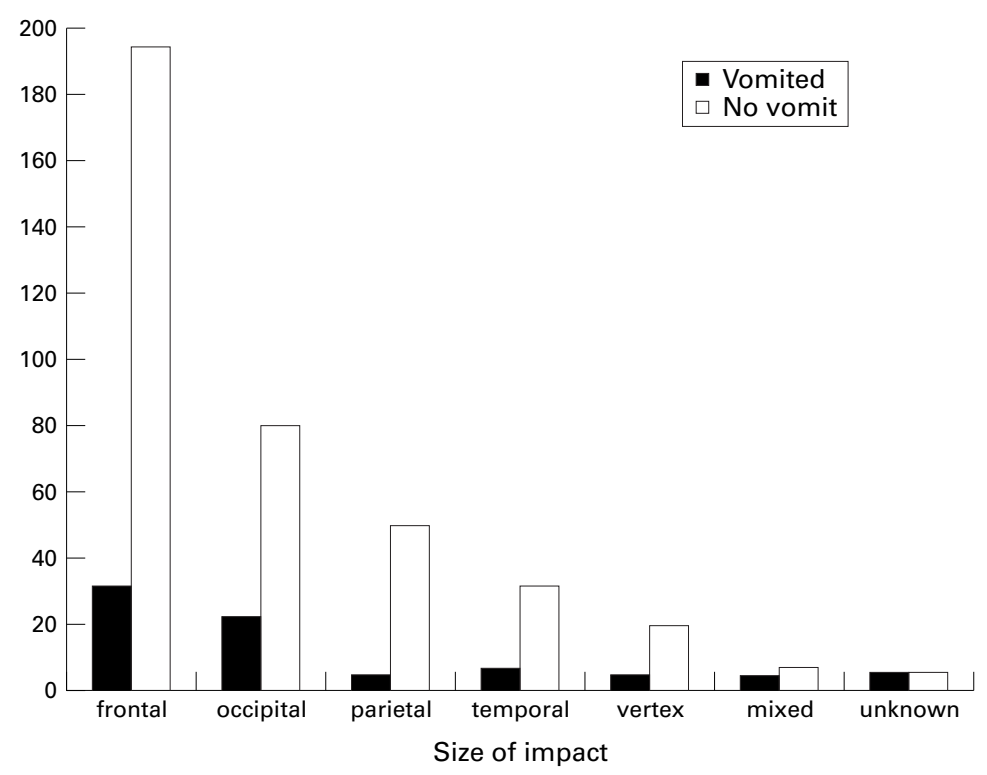

Figure 2 Site of impact and vomiting.
Diseases- 9 criteria $^{6}$ or, in the case of children, the adapted Prensky criteria. ${ }^{7}$

Patients were defined as "vomiters" or "nonvomiters". Statistical comparison between the two groups was made by $2 \times 2$ contingency tables ( $\chi^{2}$ or Fisher's exact test).

\section{Results}

A total of 563 patients presented after head injury to the $\mathrm{A} \& \mathrm{E}$ department during the two month study period. They constituted $10.4 \%$ of total attendances. The RHSC, Edinburgh provides emergency services for a population of approximately 100000 children less than 13 years old.

Six patients were excluded; four with past brain trauma or abnormality, two for social reasons. Seventy eight patients could not be contacted by phone and subsequently only limited data were available. A further 15 patient histories could not be located so no information was available on these patients. Data were complete on the remaining 462 patients ( $82 \%$ of those eligible for the study). The mean age for those with complete data was 5 years and 6 years for those lost to follow up ( $\mathrm{p}=0.8$ Mann-Whitney). Sixty seven per cent were male in both the data complete and the lost to follow up group. Seventy three $(15.8 \%)$ of the 462 data complete group vomited and nine $(11 \%)$ of the 78 lost to follow up group $\left(p=0.4 \chi^{2}\right)$.

Figure 1 gives basic demograhic details. Seventy three $(15.8 \%)$ children vomited after their head injury of whom $20(27 \%)$ vomited more than twice (mean number of vomits 5 , median 4). There was no statistical evidence that age or sex predisposed to the vomiting. Most patients sustained their injury from a fall. Most road traffic accidents involved cyclists alone (table 1). The most common site of impact was frontal (fig 2). No particular mode of injury nor site of impact was associated with an increased likelihood of vomiting after head injury.

Clinical features were reviewed. One hundred and three patients $(22.3 \%)$ sustained a scalp haematoma. One hundred and fifty seven $(34 \%)$ were investigated with a skull radio-

Table 1 Patient characteristics

\begin{tabular}{|c|c|c|c|c|c|c|c|}
\hline Factor & $\begin{array}{l}\text { Number of } \\
\text { patients with } \\
\text { factor }\end{array}$ & $\begin{array}{l}\% \text { Of } \\
\text { total } \\
\text { patients }\end{array}$ & $\begin{array}{l}\text { Number with } \\
\text { factor who } \\
\text { vomited }\end{array}$ & $\begin{array}{l}\% \text { With } \\
\text { factor who } \\
\text { vomited }\end{array}$ & $\begin{array}{l}\text { Number with } \\
\text { factor who did } \\
\text { not vomit }\end{array}$ & $\begin{array}{l}\% \text { With } \\
\text { factor who } \\
\text { did not } \\
\text { vomit }\end{array}$ & $\begin{array}{l}\text { Significance of } \\
\text { factor in } \\
\text { relation to } \\
\text { vomiting }\end{array}$ \\
\hline \multicolumn{8}{|l|}{ Family history } \\
\hline maternal migraine & 97 & 21 & 19 & 19.6 & 78 & 80.4 & NS \\
\hline paternal migraine & 20 & 4.3 & 2 & 10 & 18 & 90 & NS \\
\hline \multicolumn{8}{|l|}{ Personal history } \\
\hline male sex & 280 & 67 & 39 & 13.9 & 241 & 86.1 & NS \\
\hline migraine & 6 & 1.3 & 2 & 33 & 4 & 67 & NS \\
\hline recurrent headaches & 25 & 5.4 & 6 & 24 & 19 & 76 & NS \\
\hline recurrent vomiting & 17 & 3.7 & 7 & 41 & 10 & 59 & $\mathrm{p}=0.0035$ \\
\hline recurrent abdominal pain & 30 & 6.5 & 5 & 16.7 & 25 & 83.3 & NS \\
\hline motion sickness & 60 & 13 & 15 & 25 & 45 & 75 & $\mathrm{p}=0.036$ \\
\hline sleep disturbance & 105 & 22.7 & 21 & 20 & 84 & 80 & NS \\
\hline \multicolumn{8}{|l|}{ Injury mechanism } \\
\hline fall & 353 & 76 & 58 & 16 & 295 & 84 & NS \\
\hline road traffic accident & 54 & 11.6 & 12 & 22 & 42 & 78 & NS \\
\hline hit by object & 56 & 12 & 3 & 5 & 53 & 95 & NS \\
\hline assault & 1 & $<1$ & 0 & 0 & 1 & 100 & NS \\
\hline Skull radiography done & 157 & 34 & 38 & 24 & 119 & 76 & NS \\
\hline skull fracture & 3 & $<1$ & 0 & 0 & 3 & 100 & NS \\
\hline brain injury & 31 & 6.7 & 8 & 25.8 & 23 & 74.2 & NS \\
\hline
\end{tabular}


graph and patients who vomited were more likely to have a skull radiograph taken $(p=0.004)$. Three $(<1 \%)$ had a documented skull fracture (films were reported by a paediatric radiologist). Thirty one patients $(6.7 \%)$ had a history of LOC (all less than six minutes) or amnesia. Five of these had both. No patients had an altered conscious state on arrival to the A\&E department or on further assessments. Of the 31 with evidence of brain injury eight vomited. Vomiting after head injury was not more common if the patient sustained a scalp haematoma or a skull fracture. Children who suffered brain injury were more likely to vomit than those without brain injury ( $p$ value $=0.037$ ) but vomiting did not predict brain injury.

Comparisons were made between vomiters and non-vomiters with respect to features of their past and family histories (table 1). A statistically significant relation was found between vomiting after minor head injury and a past history of motion sickness ( $\mathrm{p}$ value $=0.036$ ) or recurrent vomiting $(\mathrm{p}$ value $=0.0035)$.

\section{Discussion}

Paediatric head injury is common. Our numbers estimates an annual incidence of 3378 head injuries/100 000, which is similar to previously published figures. ${ }^{8}$ Past studies have shown a significant male predominance and almost half those presenting to A\&E departments are less than 5 years old. ${ }^{289}$ Our population demonstrated similar age and sex demographics. Younger children may present more readily because of parental anxiety rather than them having a higher incidence of head injury. Studies from the United States tend to describe more severe head injuries reflecting issues of access to hospital care. ${ }^{12}$ In Edinburgh most patients have relatively easy access to free health care and we subsequently see a wide spectrum of head injuries, including children who are possibly managed by primary care facilities elsewhere.

Vomiting occurred in $15.8 \%$ of our analysed population, an incidence similar to previously published figures of $10-17 \% .^{2410}$ Studies that exclude the most minor injuries quote considerably higher rates, up to $35 \% .{ }^{11}$ Most would agree that vomiting does not necessarily imply a more severe head injury or brain injury but its significance remains unclear. The purpose of our study was to identify factors associated with vomiting after a head injury and therefore clarify its significance

Some authors have suggested that younger children vomit more after minor head injury than older children and adults. ${ }^{4}$ Our data failed to find any particular age group in whom vomiting was more likely to occur.

Most childhood head injuries are secondary to falls. ${ }^{12512}$ A smaller number follow road traffic accidents where, unlike adults, the majority are pedestrians or cyclists. ${ }^{10}$ In addition, similar to some other reports, we also had a significant number who sustained an object trajectory injury, ${ }^{3913}$ the objects usually being wielded by other children. Assaults are rare and occur mostly in infants (non-accidental injuries) and teenagers. Our data supported this distribution of aetiology. We did not find a significant relation between vomiting after minor head injury and the mode of injury. It has been postulated that blows to the occipital region potentially stimulate a central emetic centre thought to reside in the reticular formation of the lateral medulla. ${ }^{14}{ }^{15} \mathrm{We}$, like others, ${ }^{4}$ did not find that any one site of impact was more likely to result in vomiting after head injury than the others. One could assume that the velocity of impact and both the surface area and material of the impacting object would affect stimulation of this vomiting centre. Most of our injuries, occurred because of simple falls from standing height; possibly the mildest form of head injuries. It is difficult to accurately assess the force involved in such impact. If this could be assessed the role of trauma to a central emetic centre could be more clearly defined.

Only three skull fractures were identified, two in infants who are a high risk group. ${ }^{316-18}$ Of interest we noted, as have others, that if a child vomited they were more likely to have a skull radiograph performed. ${ }^{10}$ Like previous studies we did not find a significant relation between vomiting and skull fractures. ${ }^{316}$ None of our patients were investigated with $\mathrm{CT}$ or magnetic resonance imaging but other studies have failed to find an association between vomiting and abnormal scan results. ${ }^{13}{ }^{19}$ Lloyd et al found that the presence of neurological abnormalities was a more reliable predictor of intracranial complications than skull fractures were and they classify vomiting as a neurological symptom but they do not clarify whether vomiting alone is significant and whether or not persistent vomiting is different to fewer episodes. ${ }^{17}$ We do not think there is evidence in the literature or from our study that vomiting alone is an indication for imaging of the skull or brain.

As expected ${ }^{1}$ only a small number of our population sustained brain injury $(6.7 \%)$, less than some American studies, ${ }^{2}{ }^{13}$ indicating that we see a broader range of mild head injuries and only children less than 13 years old. These children were more likely to vomit but the converse was not true; vomiting did not predict brain injury. Vomiting may be important in conjunction with neurological signs/symptoms but its significance in isolation is still unclear.

Studies suggest there are intrinsic factors predisposing some people to vomit after head injury. ${ }^{4}$ These include family history of migraine, and a personal history of migraine or its childhood variants or associated conditions such as motion sickness. In our study population $21 \%$ of mothers and $4.3 \%$ of fathers reported suffering from migraine. Recent epidemiological studies suggest $18 \%$ of women and $6 \%$ of men are affected. ${ }^{20}$ Only six $(1.3 \%)$ children in our study had migraine and five of them were older than 9 years. Migraine prevalence in children less than 15 years old is difficult to define. Studies quote between $4 \%$ and $10 \%,{ }^{71-23}$ with an increasing prevalence with increasing age. We anticipate some of our population will develop migraine in their teens 
when the onset of migraine is more common. If we were to follow up our patients through their teens we may find a higher incidence of migraine and a significant association between vomiting after head injury and migraine may emerge. We may also find that our "recurrent vomiters" develop more migraines when they got older as this is a well recognised childhood variant of migraine. Although we found a statistically significant association between vomiting after head injury and a past history of motion sickness the relation was not as strong as other studies have found. ${ }^{5}$ Motion sickness is present in all ages but is more readily recognisable in older, verbal children. As with migraine, if we followed up our population it is possible that with increasing age and increasing recognition of motion sickness, the relation with vomiting after head injury becomes stronger.

Our data support the idea that vomiting after head injury is a result of intrinsic factors in some people. In motion sickness both peripheral and central mechanisms seem to be involved and the latter are poorly understood. ${ }^{14}{ }^{15}$ Vestibular brainstem nuclei are connected to vomiting centres on the floor of the fourth ventricle by cholinergic neurones of the reticular formation of the medulla. Neurotransmitters are also involved and some authors have hypothesised the existence of a common underlying abnormality of neurotransmitter metabolism in migraine and motion sickness. ${ }^{23}$ Trauma to the head may change the metabolism of these neurotransmitters in susceptible people.

Our study results support the hypothesis that vomiting after minor head injury is not necessarily related to specific features of the head injury. And therefore vomiting alone does not have a role in decision making regarding further investigation of skull or brain. Children need not be admitted under a surgical team for neurological observations if there is no skull fracture or evidence of brain injury. Vomiting, especially if protracted, is relevant when admission is considered for the maintenance of adequate hydration. As complications are rare after head injury a larger national study reviewing minor head injury investigation and management would better define the significance of post-traumatic vomiting. Consequently, the large number of children who present to $\mathrm{A} \& \mathrm{E}$ departments with this usually benign condition may be spared unnecessary investigations (often involving exposure to radiation) and admissions, which in turn will cause less distress to patients and their families and will lessen the burden on valuable and limited resources.

Contributors

Fiona Brown initiated the study, performed the background literature search, designed the study hypothesis, formulated the study design, designed the data collection sheet, collected and interpreted the data and wrote the paper. Judith Brown particiinterpreted the data and wrote the paper. Judith Brown participated significantly in data collection and discussed core ideas with the other authors. Thomas Beattie participated in the study
design, discussed core ideas, interpreted the data especially the design, discussed core ideas, interpreted
statistical analysis, and edited the paper.

Funding: none.

Conflicts of interst: none.

1 Jennett B. Epidemiology of head injury. $\mathcal{F}$ Neurol Neurosurg Psychiatry 1996;60:362-9.

2 Hahn YS, McLone G. Risk factors in the outcome of children with minor head injury. Pediatrc Nurosurg 1993;19: 135-42.

3 Leonidas JC, Ting W, Binkiewicz A, et al. Mild head trauma in children: When is a roentgenogram necessary? Pediatrics 1982;69:139-43

4 Ando S, Otani M, Moritake K. Clinical analysis of post traumatic vomiting. Acta Neurochir 1992;119:97-100.

5 Jan MMS, Camfield PR, Gordon K, et al. Vomiting after mild head injury is related to migraine. F Pediatr 1997;130 mild head

6 Dalessio DJ. Diagnosing the severe headache. Neurology1994;44 (suppl 3):S6-12.

7 Prensky AL, Sommer D. Diagnosis and treatment of migraine in children. Neurology 1979;29:506-10.

8 Beattie TF. Minor head injury. Arch Dis Child 1997;76:825.

9 Casey R, Ludwig S, McCormack MC. Morbidity following minor head trauma in children. Pediatrics 1986;78:497502.

10 Brookes M, MacMillan R, Cully S, et al. Head injuries in accident and emergency departments. How different are children from adults? F Epidemiol Community Health 1990; 44:147-51.

11 Shunk JE, Rogerson JD, Woodward GA. The utility of head computed tomographic scanning in pediatric patients with normal neurologic examination in the emergency department. Pediatr Emerg Care 1996;12:160-5.

12 Pascucci RC. Head trauma in the child. Intensive Care Med 1988;14:185-95.

13 Mitchell KA, Fallat ME, Raque GH, et al. Evaluation of minor head injury in children. $\mathcal{F}$ Pediatr Surg 1994;29:8514.

14 Carpenter DO. Neural mechanism of emesis. Can $\mathcal{F}$ Physiol Pharmacol 1990;68:230-6.

15 Lawes INC.The origin of the vomiting response: a neuroanatomical hypothesis. Can $\mathcal{f}$ Physiol Pharmacol 1990;68:254-9.

16 Greens DS, Shutzman SA. Infants with isolated skull fracture: what are their clinical characteristics and do they require hospitalization? Ann Emerg Med 1997;30:253-9.

17 Lloyd DA, Carty H, Patterson M, et al. Predictive value of skull radiography for intracranial injury in children with skull radiography for intracranial injury
blunt injury. Lancet 1997;349:821-4.

18 Loroni L, Ciucci G, Piccinini G, et al. Approach to head trauma in childhood in a district general hospital. Eur $\mathcal{F}$ Emerg Med 1996;3:141-8.

19 Quayle KS, Jaffe DM, Kuppermann N, et al. Diagnostic testing for acute head injury in children: when are head computed tomography and skull radiographs indicated? Pediatrics 1997;5:p.e11

20 Solomon S. Migraine diagnosis and clinical symptomatology. Headache 1994;34:S8-12.

21 Gascon GG. Chronic and recurrent headaches in children and adolescents. Pediatr Clin North Am 1984:31:1027-51.

22 Abu-Arafeh I, Russell G. Prevalence and clinical features of abdominal migraine compared with those of migraine headache. Arch Dis Child 1995;72:413-17.

23 Barabas G, Matthews WS, Ferrari M. Childhood migraine and motion sickness. Pediatrics 1983;72:188-90. 